\title{
Shear creep characteristics of weak carbonaceous shale in thick layered Permian limestone, southwestern China
}

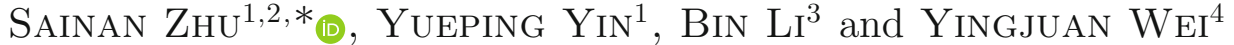 \\ ${ }^{1}$ China Institute of Geo-Environment Monitoring, Beijing 100081, People's Republic of China. \\ ${ }^{2}$ School of Engineering and Technology, China University of Geosciences, Beijing 100083, \\ People's Republic of China. \\ ${ }^{3}$ Institute of Geo-Mechanics, Beijing 100081, People's Republic of China. \\ ${ }^{4}$ China Aero Geophysical Survey and Remote Sensing Center for Land and Resources, Beijing 100083, \\ People's Republic of China. \\ *Corresponding author. e-mail: 6057817@qq.com
}

MS received 4 September 2017; revised 24 April 2018; accepted 28 April 2018; published online 19 January 2019

Several weak intercalations of carbonaceous shale, which are commonly developed in the Permian thick limestone strata in Wulong County, Chongqing, southwestern China, form a structure of alternating layers of soft and hard rocks, which control the stability of massive layered rockslides. We focus on the Permian carbonaceous shale and analyse its mineral composition, microstructure and shear creep characteristics during the three evolutionary stages. The analysis results indicate the following: (i) During the evolutionary process of the carbonaceous shale, the microstructure changed from compact to loose, and the clay mineral content gradually increased from less than $5 \%$ in the original soft rock to $5-10 \%$ in the interlayer shear zone, and finally to greater than $10 \%$ in the sliding zone. (ii) Under the identical shear stress, the creep displacement and rate gradually increase nonlinearly. Under the identical normal stress, the long-term shear strength gradually decreases, and the drop in cohesion is greater than the internal friction angle. (iii) We established an improved Burgers nonlinear damage creep model, which fully reflected the creep deformation process of the carbonaceous shale. The fitting curve of the model matched the experimental results well.

Keywords. Carbonaceous shale; weak intercalation; shear creep; long-term strength; nonlinear damage creep model; evolutionary process.

\section{Introduction}

Because of tectonic movement in the area, the limestone mountains located in southwestern China mostly form large-scale folded mountains as well as alpine canyons due to long-term intense geologic uplift and deep river erosion. There are several layers of weak intercalations of carbonaceous shale in the hard limestone stratum of the Permian thick layer in this area, and the thickness is generally
10-30 cm, forming a discontinuous soft structure surface. The carbonaceous shale and the limestone form the 'binary structure' of soft and hard rocks, which controls the stability of massive layered rockslide (Yin et al. 2011; Li et al. 2015). For instance, the sliding zones of the Jiweishan rockslide in Wulong county, Chongqing, and the Lianziya dangerous rockmass of the Three Gorges on the Yangtze River are all the result of this weak intercalation (Yin et al. 2000; Feng et al. 
2012). During the deformation and development of a layered rockslide, the weak intercalations exhibit significant creep deformation after long-term geological evolution. Therefore, the creep mechanical characteristics of the weak intercalations become the key scientific issue in studying the causes of instability in layered rockslides.

Previous studies classified the weak intercalations based on their composition, microstructure, causes, etc. In general, the weak intercalations are divided into four types: the original soft rock, the interlayer shear zone (staggered zone), the siltized intercalation and the sliding zone ( $\mathrm{Gu}$ 1983). Qu and $\mathrm{Xu}$ (1983) and Li et al. (2008) discussed the formation of a weak intercalation, they assumed that for soft and hard interbedded rocks of various strengths under the tectonic action, an interlayer force was produced between the soft and hard rocks forming contact surfaces or internal soft rock surfaces, which resulted in damage to the original soft rock structure and formation of an interlayer shear zone. Later, due to hydration and gravity, the interlayer shear zone forms a siltized intercalation and sliding zone, which has a loose structure and weak cohesion.

The weak intercalation is a typical elasticviscous-plastic system, and the creep deformation is key to the stability of the discontinuous rockmass, and the stress and strain are significantly affected by time ( $\mathrm{Li}$ and Kang 1983; Maranini and Brignoli 1999). As early as the end of the 1930s, Griggs (1939) studied the creep characteristics of shales, sandstones and limestones. The results indicated that creep deformation of rock generally occurred when the stress reached 12.5$80 \%$ of the maximum rupture stress. In 1959, Chen carried out the rheological tests of the surrounding rock of the Three Gorges on Yangtze River and put forward the concept of long-term strength of a rockmass, the method for its determination and the constitutive equation for its calculation. In addition, he performed experiments on the creep and relaxation characteristics of the siltized intercalation of the dam foundation of the Gezhouba Dam and proposed a design for a dam type with siltized intercalation (Tan and Li 1994). Perzyna (1966) proposed the elastic-viscoplastic theory of rocks. Later, Zienkiewicz and Cormeau (1974), Desai and Zhang (1987), etc. improved this theory to establish the overall framework of an elastic-viscoplastic model, which was applicable to the analysis of the creep of rocks and soils. Xiao et al. (1987) carried out the shear creep testing on the siltized intercalation and developed empirical equations for the initial creep stage, the steady-state creep stage and the accelerated creep stage. Savage and Varnes (1987) assumed that the creep deformation of the interlayer shear zone led to plastic flow inside the deep slope. Sun (2007) established a rheological model, which describes the complicated rheological mechanical characteristics of the rock, and used this model to identify the loading-unloading curve parameters of creep under various levels of stress.

From the current research at home and abroad, studies of the weak intercalations mostly focused on a single evolutionary stage or the engineering geotechnical and mechanical properties of the sliding zone (Paul and Christian 1996; L'Heureux et al. 2012; Xu et al. 2012; Zhu and Yu 2014). There are few comparisons and analysis on the variation of the mechanical creep characteristics from the perspective of long-term evolution. Therefore, this paper focuses on the weak intercalations of the Permian carbonaceous shale, using an X-ray diffractometer, a scanning electron microscope and a CQZJ-2015 shear testing apparatus to carry out the mineral composition, the microstructures and the creep shear tests of different evolutionary stages (original soft rock, interlayer shear zone and sliding zone). Based on a detailed analysis of our experimental results, we introduced a damage variable and established the nonlinear damage creep model applicable to the carbonaceous shale. This paper provides important information for the investigation of the initiation, development and instability mechanism of layered rockslides controlled by weak intercalations.

\section{Geological conditions and carbonaceous shale characteristics}

\subsection{Geological conditions}

The study area is located in the southeast edge of the Sichuan basin of China and belongs to the Neocathaysian tectonic system, which is formed by the second phase of the Yanshan movement. The strata in the study area are sedimentary rocks with Cambrian, Ordovician, Silurian, Permian, Triassic and Jurassic. In addition to the Permian and Silurian are the disconformity contacts, the other is the conformity contact (Chen and Xiao 1955; Li et al. 2002; Yin et al. 2011).

The strata situation of the study area is as follows (figure 1): 


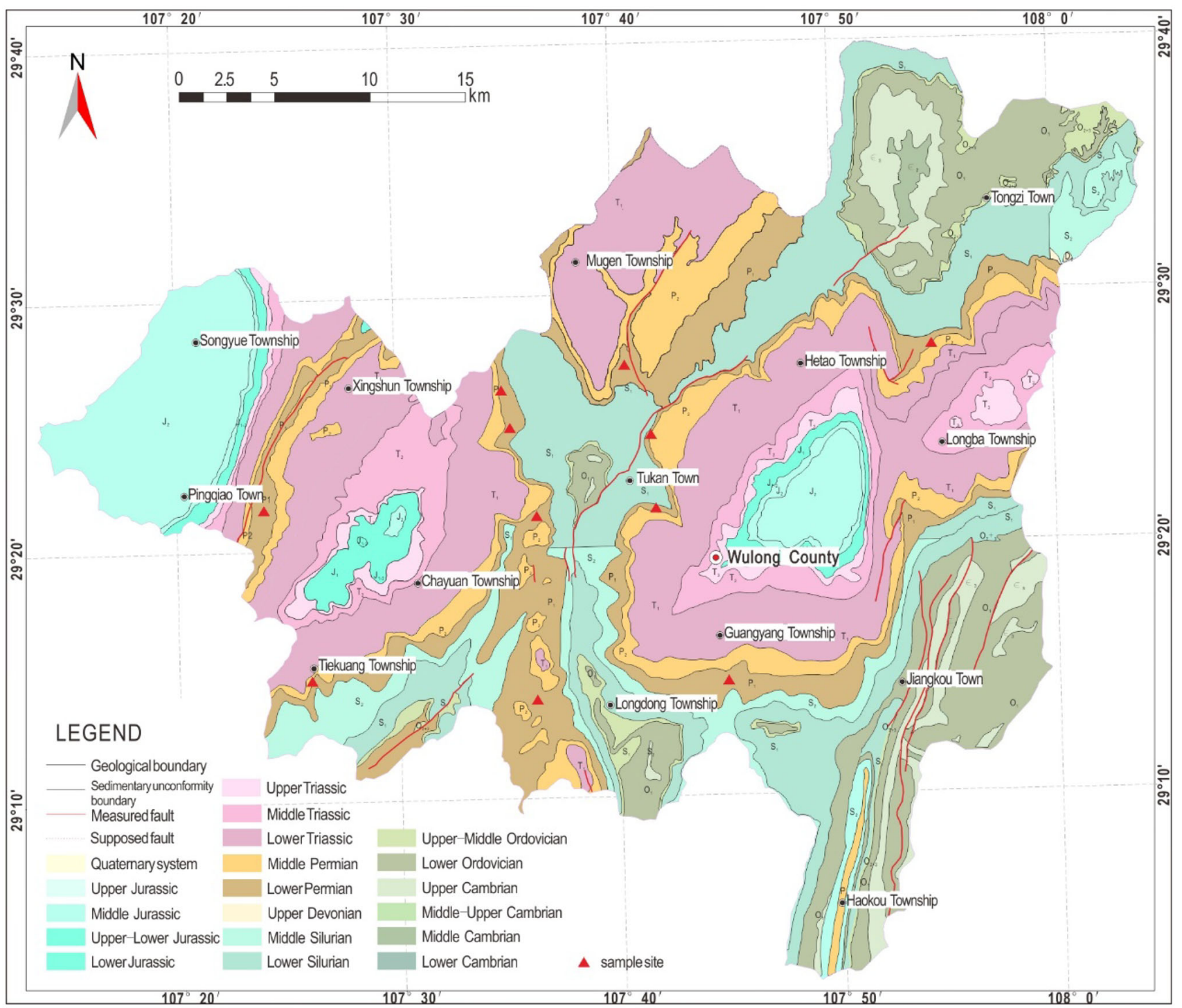

Figure 1. Geological map and sample sites of the study area (modified after Chen and Xiao 1955 and Li et al. 2002).

(1) The Cambrian $(\epsilon)$ is distributed in the anticlinal core, and the lithology is dominated by the dark grey dolomite limestone, with shale, sandstone, etc. The total deposition thickness is greater than $1230 \mathrm{~m}$.

(2) The Ordovician $(\mathrm{O})$ is widely distributed in the area, and lithology is composed of limestone and shale, with a total deposition thickness of 468-650 m.

(3) The Silurian (S) is widely distributed in the region, and the lithology is the shale rock and limestone, with a total deposition thickness of about $1250 \mathrm{~m}$.

(4) The Permian (P) is exposed to the syncline wing, including coal, iron, aluminium and other strata. The lithology is limestone with carbonaceous shale with a total deposition thickness of about $650 \mathrm{~m}$.
(5) The Triassic $(\mathrm{T})$ is widely distributed in the area, which is exposed to the anticlinal wing, and the lithology is sandstone and limestone, with a thickness of $1676 \mathrm{~m}$.

(5) The Jurassic ( $\mathrm{J}$ ) is widely distributed in the region, and the lithology is sandstone and mudstone, with a deposition thickness of $2836 \mathrm{~m}$.

In this paper, the weak intercalation samples are taken from Wulong County, Chongqing, China, and the site of the samples is shown in figure 1 . The lithology is both the Permian carbonaceous shale, deep black, stratified structure and the thickness is generally $0.1-0.3 \mathrm{~m}$, with a calcite vein. The carbonaceous shale structure which is undisturbed by tectonic movement is intact and has a high strength, while that which is disturbed by tectonic movement is loose and has a low strength. 


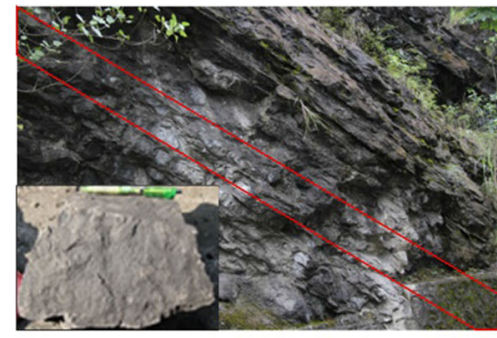

Original soft rock

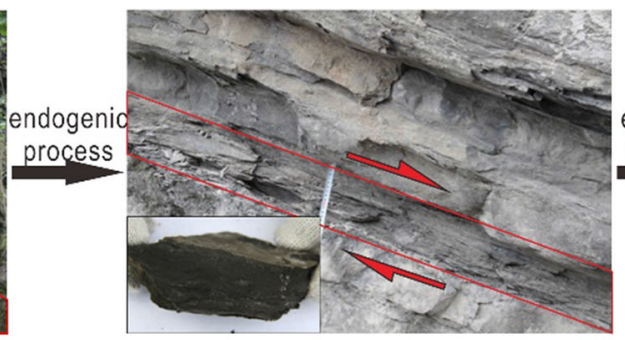

Interlayer shear zone

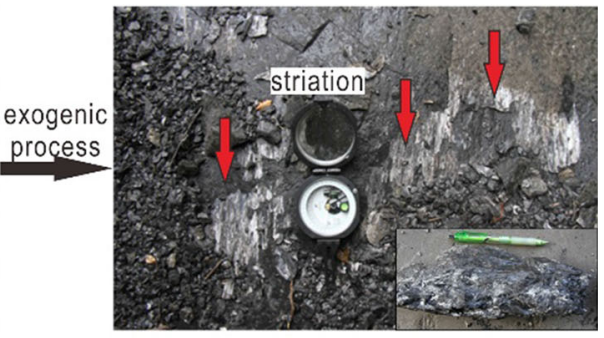

Sliding zone

Figure 2. Evolution pattern of the Permian carbonaceous shale.

Table 1. Mineral component and content of the carbonaceous shale.

\begin{tabular}{lcccccccc}
\hline & \multicolumn{7}{c}{ Mineral content (\%) } \\
\cline { 2 - 8 } Evolutionary stage & Quartz & Calcite & Dolomite & Pyrite & Jarosite & Talc & Montmorillonite & Chlorite \\
\hline Original soft rock & 14.9 & 47.6 & 33.0 & 0.2 & - & 2.3 & 0.9 & 1.2 \\
Interlayer shear zone & 14.7 & 61.8 & 14.5 & 0.6 & - & 3.2 & 3.3 & 1.9 \\
Sliding zone & 15.3 & 53.6 & 5.5 & 0.5 & 8.2 & 5.8 & 7.3 & 3.8 \\
\hline
\end{tabular}

According to the causes and evolution of weak intercalations, they can be divided into three categories: the original soft rock samples from a stable slope, the interlayer shear zone samples from an unstable slope and the sliding zone samples from the Jiweishan rockslide ( $\mathrm{Li}$ et al. 2008; Yin et al. 2011; Feng et al. 2012), as shown in figure 2.

\subsection{Mineral composition characteristics}

The mineral composition of the carbonaceous shale was determined using a D8 Advance X-ray distractor, and the samples consisted of 10 groups of each of the original soft rock, the interlayer shear zone and the sliding zone. The average values of the experimental results are given in table 1.

The change in the carbonaceous shale is based on the parent rock during the evolutionary process. From table 1, the following can be concluded: (i) The minor increase in quartz content of the sliding zone may be related to the parent rock or adjacent strata. One reason is that the quartz content in the samples of parent rock is slightly higher than that of other samples. Another reason is the quartz content in adjacent limestone is high. In the slide process, a small amount of limestone is carried in the sliding zone, which causes a minor increase in the quartz content. (ii) The calcite content remains high. This is because the calcium carbonate dissolved in the karst groundwater seeps in and is deposited in the cracks of the carbonaceous

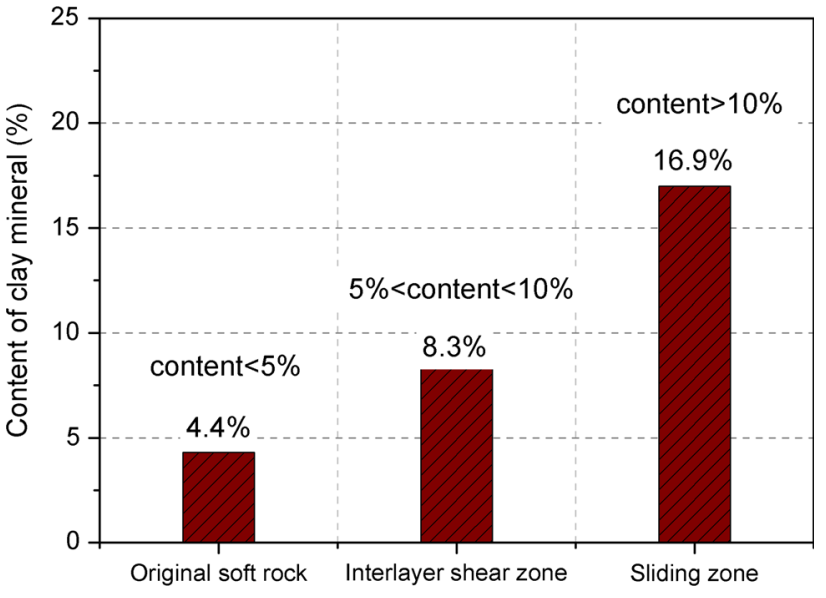

Figure 3. Mean content of the clay mineral.

shale during formation of the late sliding zone, the full participation of this water results in hydrolysis and dissolution of calcite, which decreases the calcite content. (iii) The amount of dolomite decreases from $33.0 \%$ to $5.5 \%$. This indicates that it participates throughout the evolution of the carbonaceous shale, in which $\mathrm{Ca}^{2+}, \mathrm{Mg}^{2+}$ and other exchangeable cations reacting with the water and other minerals.

The mean content of the clay mineral in the carbonaceous shale is shown in figure 3. (i) The clay minerals are mainly composed of montmorillonite, chlorite and talc, of which montmorillonite and chlorite have strong hydrophilia and swelling shrinkage. When clay minerals absorb water, the expansion pressure exceeds the overlying rock pressure, the weak intercalation's structure is damaged, 


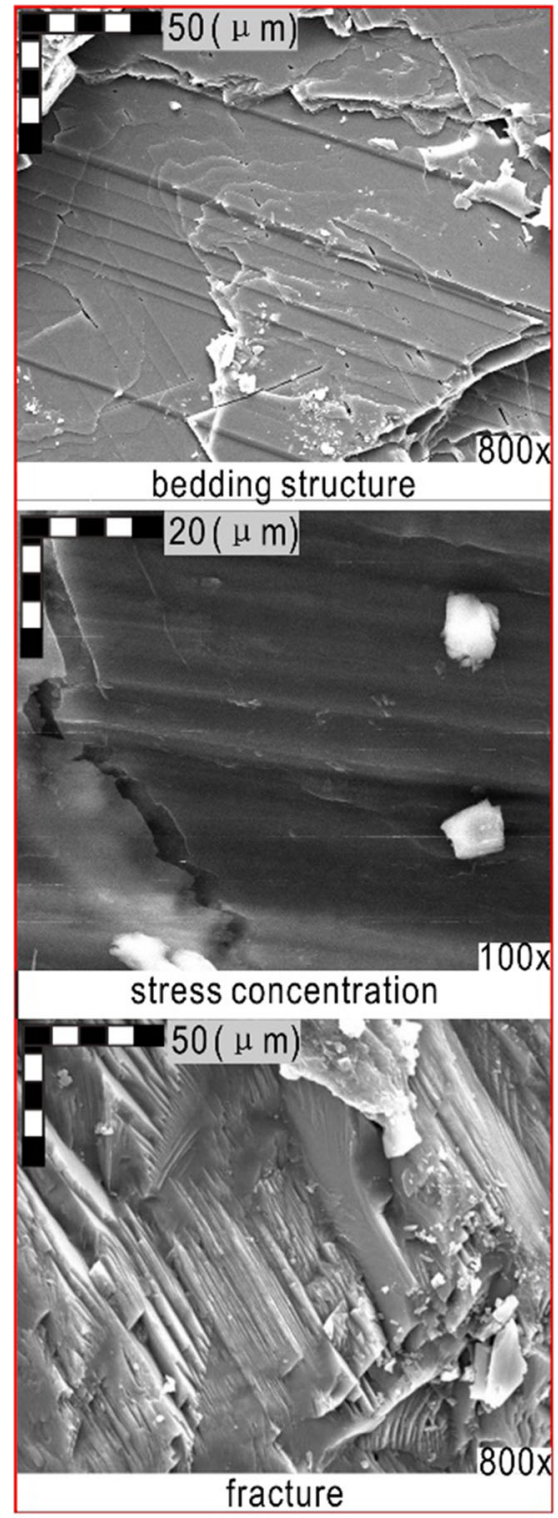

Original soft rock

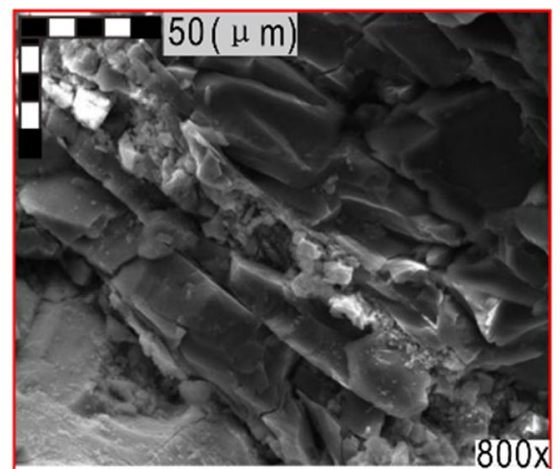

structural damage

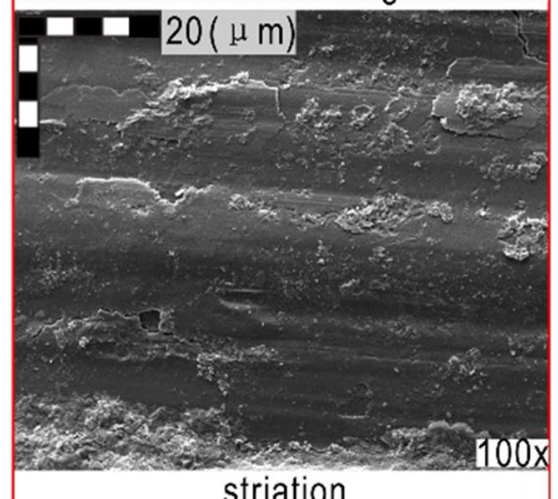

striation

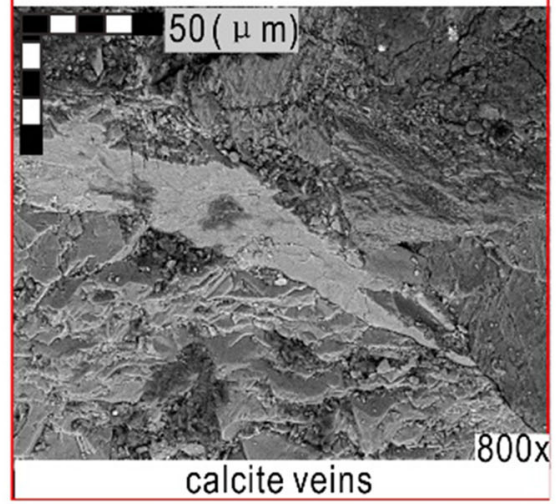

Interlayer shear zone

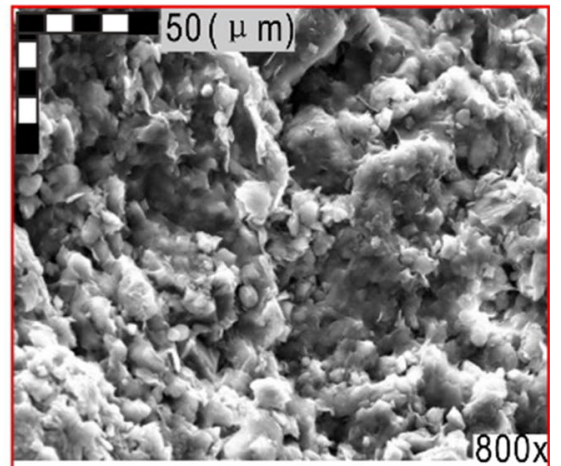

cellular structure

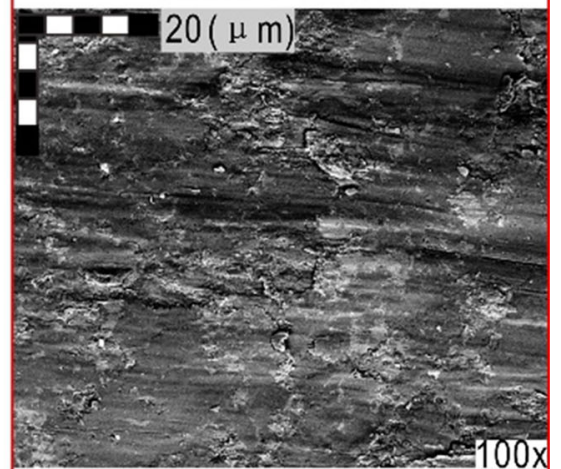

increasing striation

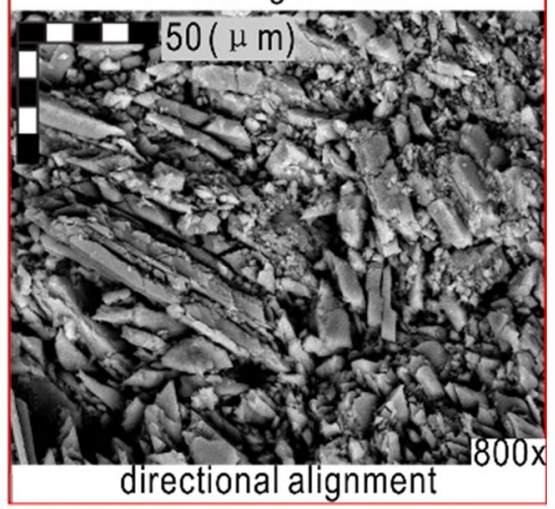

Sliding zone

Figure 4. Evolutionary process of the microstructure.

its strength decreases and creep-slide occurs. After dewatering, the clay minerals shrink, and the creepslide deformation of the mountain is accelerated. In addition, when subjected to a shear force, montmorillonite and chlorite undergo particle rearrangement and are prone to form shear surfaces. (ii) Talc is very soft with a creamy feel. This decreases the strength and is also one of the factors responsible for the long-term creep slide. According to a large amount of statistical experimental results, we can find out that the clay mineral content is less than $5 \%$ for the original soft rock, between $5 \%$ and $10 \%$ for the interlayer shear zone and greater than $10 \%$ for the sliding zone.

\subsection{Microstructural characteristics}

A Quanta 250 SEM was used to determine the microstructure of the carbonaceous shale. The samples consisted of 10 groups, each from the original soft rock, the interlayer shear zone and the sliding zone. The analysed representative test results were shown in figure 4.

The test results indicate the following: (i) The microstructure of the original soft rock is layered, the interlayer connection is compact and the stretching effect forms ragged cracks and fractures. (ii) The microstructure of the interlayer shear zone is a skeleton, the connecting force of 


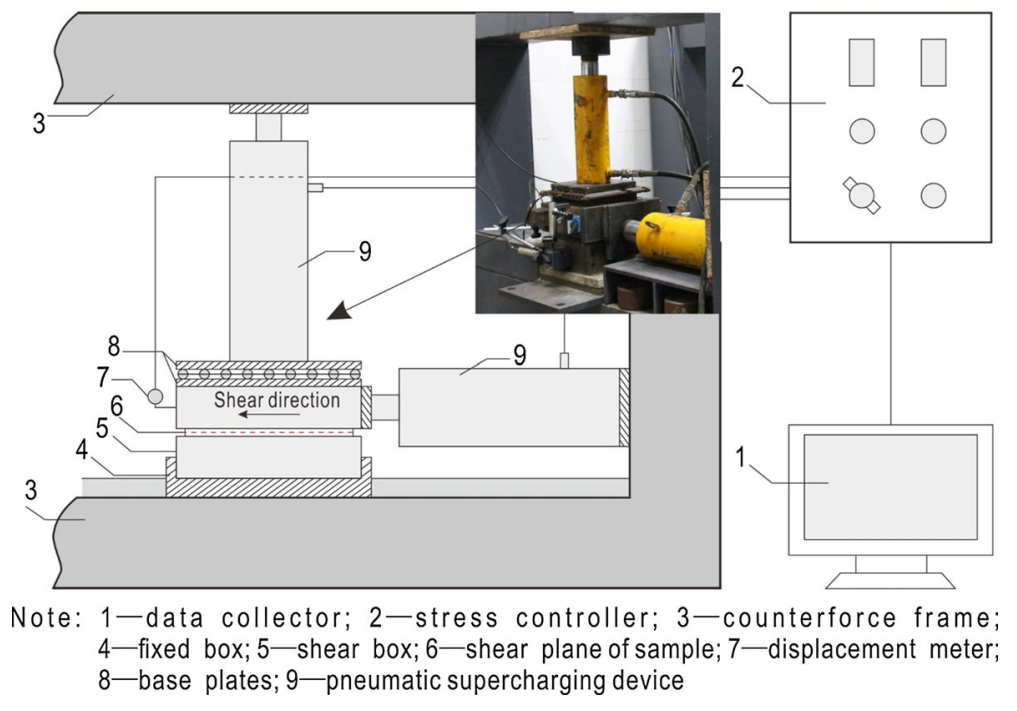

Figure 5. CQZJ-2015 shear creep apparatus.

Table 2. Testing scheme of shear creep of the carbonaceous shale.

\begin{tabular}{|c|c|c|c|c|c|c|c|c|}
\hline \multirow{2}{*}{$\begin{array}{l}\text { Evolutionary } \\
\text { stages }\end{array}$} & \multirow{2}{*}{$\begin{array}{c}\text { Normal stress } \\
\sigma(\mathrm{MPa})\end{array}$} & \multirow{2}{*}{$\begin{array}{l}\text { Shearing area } \\
\qquad A\left(\mathrm{~cm}^{2}\right)\end{array}$} & \multicolumn{6}{|c|}{ Step of shear stress $\tau(\mathrm{MPa})$} \\
\hline & & & Step 1 & Step 2 & Step 3 & Step 4 & Step 5 & Step 6 \\
\hline \multirow[t]{3}{*}{ Original soft rock } & 0.7 & 361 & 0.496 & 0.870 & 1.305 & 1.725 & 2.176 & - \\
\hline & 1.5 & 310 & 0.669 & 1.513 & 2.909 & 3.835 & - & - \\
\hline & 2.3 & 540 & 0.844 & 1.745 & 2.437 & 3.345 & 4.218 & 4.945 \\
\hline \multirow[t]{3}{*}{ Interlayer shear zone } & 0.7 & 324 & 0.216 & 0.432 & 0.648 & 0.864 & 1.080 & 1.296 \\
\hline & 1.5 & 280 & 0.500 & 1.000 & 1.375 & 1.468 & - & - \\
\hline & 2.3 & 351 & 0.840 & 1.260 & 1.680 & 2.100 & 2.520 & 2.917 \\
\hline \multirow[t]{3}{*}{ Sliding zone } & 0.5 & 263 & 0.100 & 0.190 & 0.290 & 0.390 & 0.590 & - \\
\hline & 1.0 & 243 & 0.250 & 0.490 & 0.740 & 0.900 & - & - \\
\hline & 1.5 & 283 & 0.330 & 0.680 & 1.020 & 1.330 & - & - \\
\hline
\end{tabular}

Notes: All samples have natural status.

the loosening frame between the particles is weak and the amount of micropores has increased. Since the calcite veins formed by the karst process were deposited in the joints and fissures, there were some directional scratches on the layer's surfaces with a frequency of 40-60 scratches/cm. (iii) The microstructure of the sliding zone is a skeleton honeycomb, and the bonding force is weak. The frequency of scratches on the layer's surface is higher than the interlayer shear zone, which is about $80-120$ scratches $/ \mathrm{cm}$. The size of the debris particles in the sliding zone is different, and they exhibited apparent directional arrangement. This microstructure provides favourable conditions for rock creep deformation and failure (Shi et al. 2013).

\section{Experimental method}

This study included shear creep experiments on the original soft rock, the interlayer shear zone and the sliding zone. Each stage was represented by three samples, making a total of nine samples. A CQZJ-2015 shear apparatus was used to conduct the experiments (figure 5). This apparatus features high precision, reliable performance and good stability. It meets the experimental requirements. The detailed experimental design is shown in table 2 .

During the experiments, the indoor temperature was controlled at a constant $25^{\circ} \mathrm{C}$. First, the rock samples and displacement sensors were installed. Second, the normal stress was applied uniformly after the reading of displacement sensors stabilised. Third, when the normal stress reached a predetermined value and remained constant, the shear stress was applied in steps. In particular, the shear stress applied to each sample was loaded in at least four steps, and the next step of shear stress was applied after the former step of displacement had stabilised. In this way, the samples were loaded in steps until the creep failure occurred. It should be 
noted that the criteria for displacement stability included the observation time after each step of loading shear stress was $>5$ days, the average value of horizontal displacement did not vary more than $\pm 2 \mu \mathrm{m} / \mathrm{d}$, and the steady-state time was $>2$ days.

\section{Analysis of experimental results}

\subsection{Creep displacement-time variation rules}

The resulting data was processed into creep curves using the Boltzmann linear superposition principle under the condition of step loading. The shear creep displacement-time curves for the original soft rock, the interlayer shear zone and the sliding zone were shown when $\sigma=1.5 \mathrm{MPa}$ (figure 6). The results indicate that the carbonaceous shale exhibits apparent creep characteristics, and the corresponding creep curves can be divided into three deformation stages: (i) An initial creep stage, in which the rock samples all exhibited instant creep deformation when the shear stress loading was stepped up. This stage had a short duration and a large displacement. As shown in figure 6(a), when $\tau=0.669 \mathrm{MPa}$, the initial creep stage lasted $0.17 \mathrm{hr}$ and the displacement reached $0.16 \mathrm{~mm}$. (ii) A steady-state creep stage, which occurred after the initial creep was complete, and the deformation entering the steady-state creep stage. This stage had a longer duration, and the corresponding creep curve was approximately a straight line. The displacement basically remained unchanged or exhibited slow growth at a uniform speed. As shown in figure $6(\mathrm{a})$, when $\tau=0.669 \mathrm{MPa}$, the steady-state creep stage lasted $118.89 \mathrm{hr}$ and the corresponding displacement was $0.024 \mathrm{~mm}$. (iii) An accelerated creep stage occurred during the last shear stress loading step, during which the rock samples exhibited accelerated creep deformation. This stage also had a short duration and a large shear displacement. Finally, the rock samples failed due to creep deformation. As shown in figure 6(a), when $\tau=3.835 \mathrm{MPa}$, the accelerated creep stage lasted $0.008 \mathrm{hr}$ and the corresponding displacement was $0.097 \mathrm{~mm}$.

Figure 7 shows the shear stress-displacement isochronous curves for the carbonaceous shale at three stages with $\sigma=1.5 \mathrm{MPa}$ and creep times at 0.2 and $60 \mathrm{hr}$. It was observed that the isochronous curve had nonlinear characteristics. With an increase of shear stress, the creep displacement gradually increased. Under identical shear
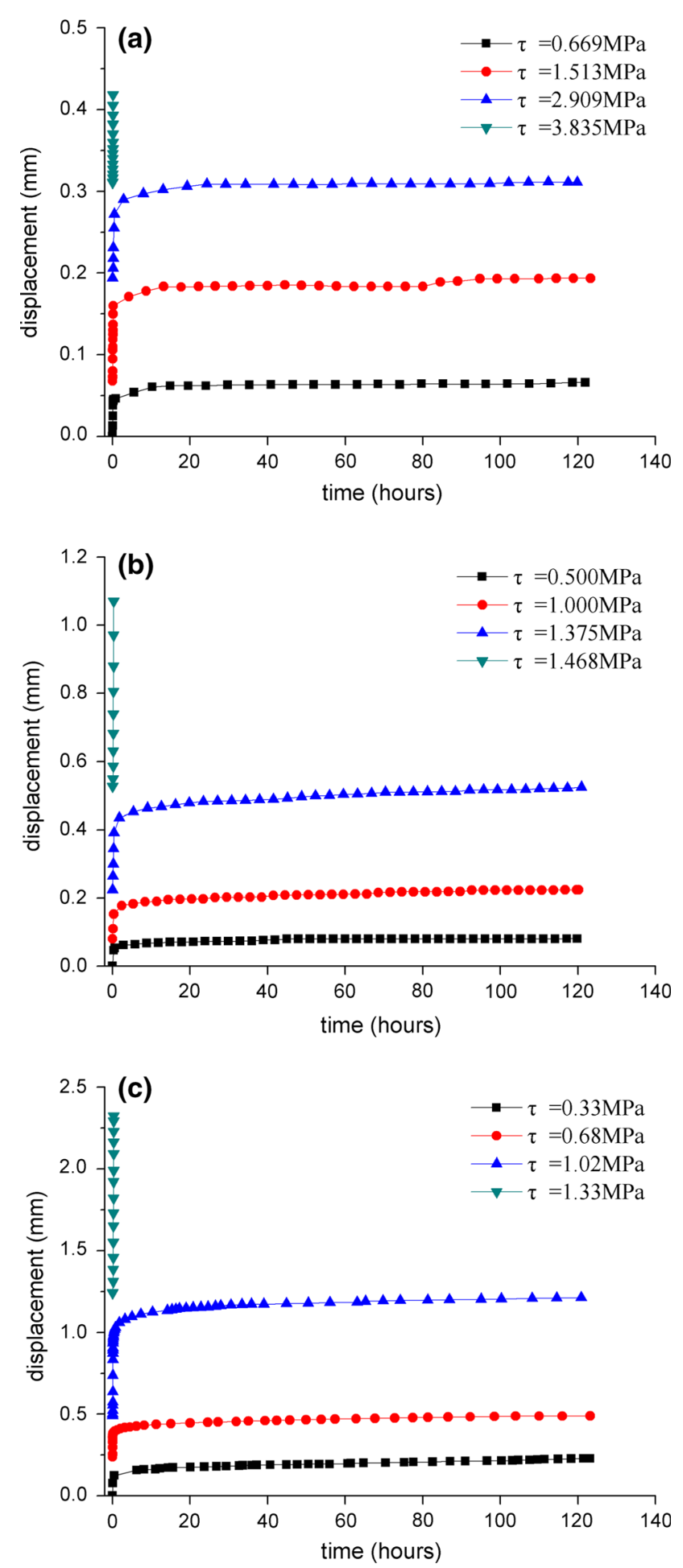

Figure 6. Creep curves of displacement-time when $\sigma=$ 1.5 MPa: (a) shows the original soft rock; (b) shows the interlayer shear zone; and (c) shows the sliding zone.

stress, the creep displacement of the sliding zone was greater than that of the interlayer shear zone and that of the interlayer shear zone was greater than that of the original soft rock. This relationship was caused by the different amounts of defects, 


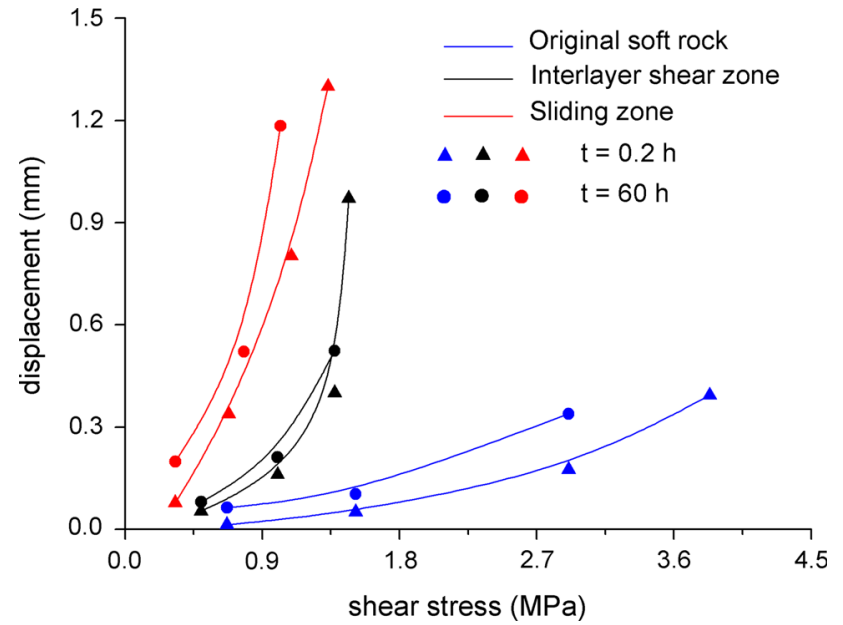

Figure 7. Isochronous curves of shear stress-displacement under three stages.

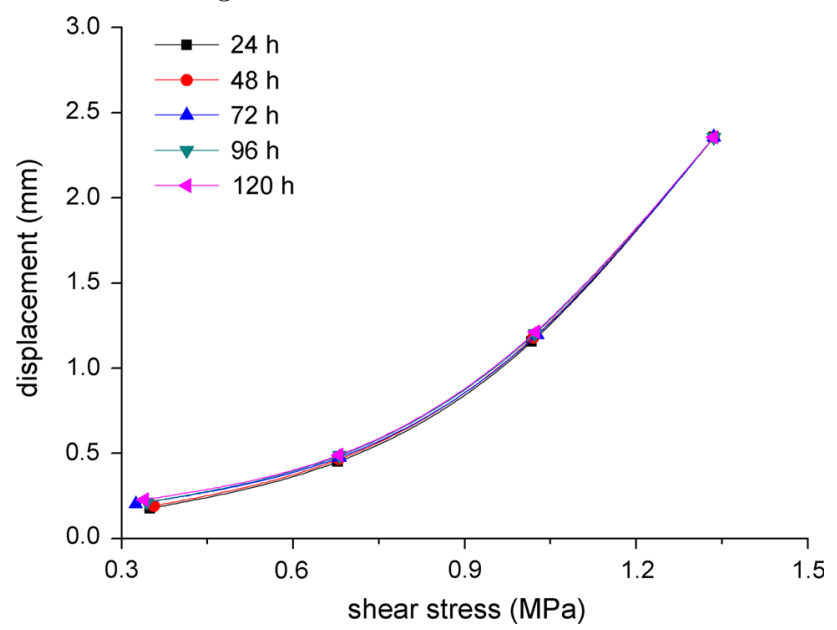

Figure 8. Isochronous curves of shear stress-displacement of sliding zone.

pores and holes inside the rock samples of the carbonaceous shale.

Figure 8 shows the shear stress-displacement curves for the carbonaceous shale at various stages when $\sigma=1.5 \mathrm{MPa}$. It was not difficult to determine that the isochronous curves had nonlinear characteristics and that the creep displacements at various times increased with increasing shear stress. Under the identical shear stress, the creep displacements at various times did not vary significantly. The long-term shear strength of the carbonaceous shale can be determined according to isochronous curves ( $\mathrm{Li}$ and Kang 1983).

\subsection{Factors controlling the creep rate}

The relationship between the creep displacement and rate with time at the last shear stress step of the sliding zone is shown in figure 9. Creep rate

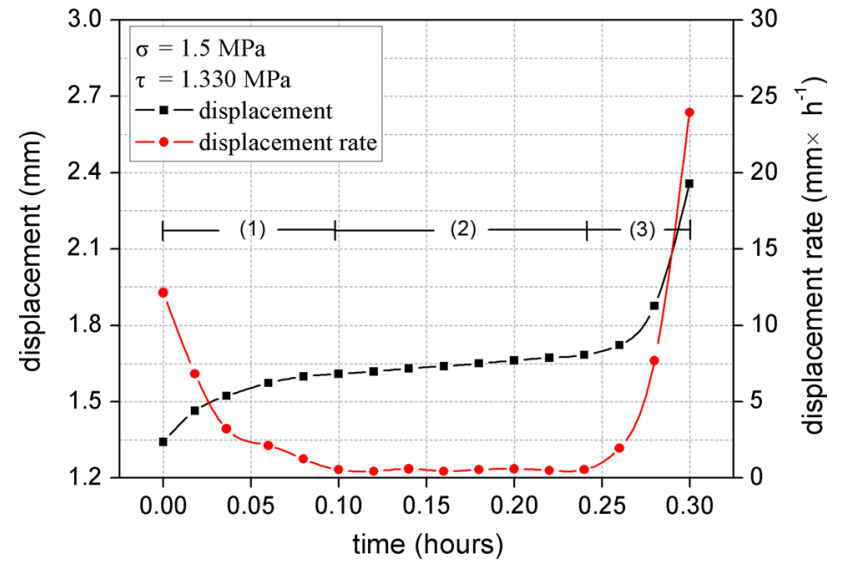

Figure 9. Curves of displacement and displacement rate with time: (1) shows the creep rate decay stage; (2) shows the uniform creep rate stage; and (3) shows the accelerated creep stage.

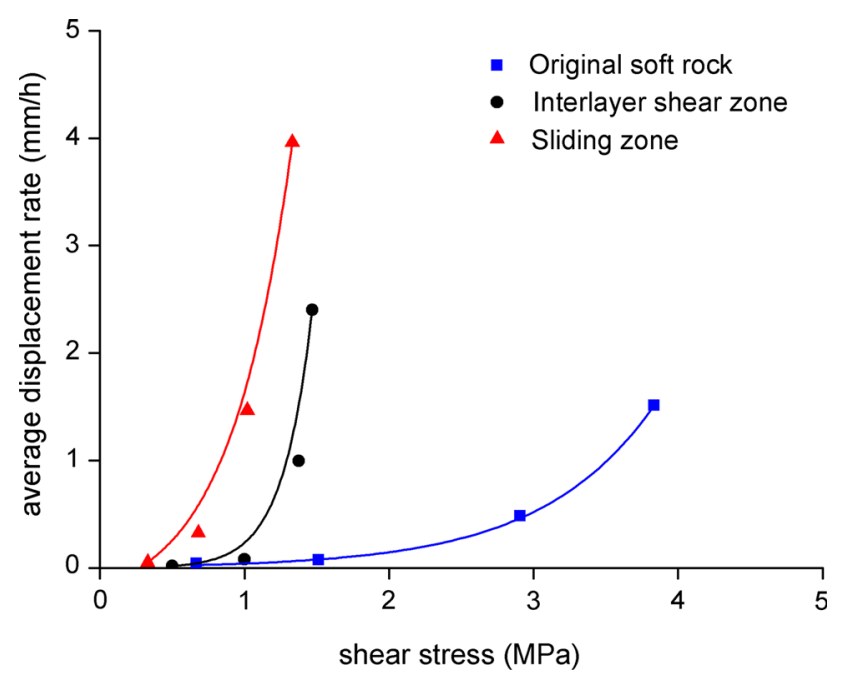

Figure 10. Curves of shear stress-average displacement rate under three stages.

can be divided into three stages: (i) The creep rate decay stage, in which the creep rate continuously decreases and decays to a non-zero constant. (ii) The uniform creep rate stage, in which the creep rate basically remains constant at zero or another constant value. (iii) The accelerated creep stage, in which the creep rate dramatically increases until the rock sample fails. These three stages correspond to the initial creep stage, steady-state creep stage and accelerated creep stage of the creep displacement-time curve, respectively.

We calculated the slopes of each moment of the creep curves corresponding to the carbonaceous shale and obtained shear stress-average creep rate curves (figure 10 , when $\sigma=1.5 \mathrm{MPa}$ ). It was observed that with increasing shear stress, the average creep rate gradually increased. Under 
Table 3. Parameters of creep rate of the carbonaceous shale.

\begin{tabular}{lrlllc}
\hline Evolutionary stages & $a\left(10^{-2}\right)$ & $b\left(10^{-2}\right)$ & $\alpha\left(10^{-2}\right)$ & $\beta\left(10^{-2}\right)$ & $R^{2}$ \\
\hline Original soft rock & 0.204 & 4.178 & 103.107 & 78.088 & 0.997 \\
Interlayer shear zone & -0.208 & 50 & 2.008 & 20.229 & 0.995 \\
Sliding zone & -36.560 & 41.960 & 33 & 42.846 & 0.993 \\
\hline
\end{tabular}

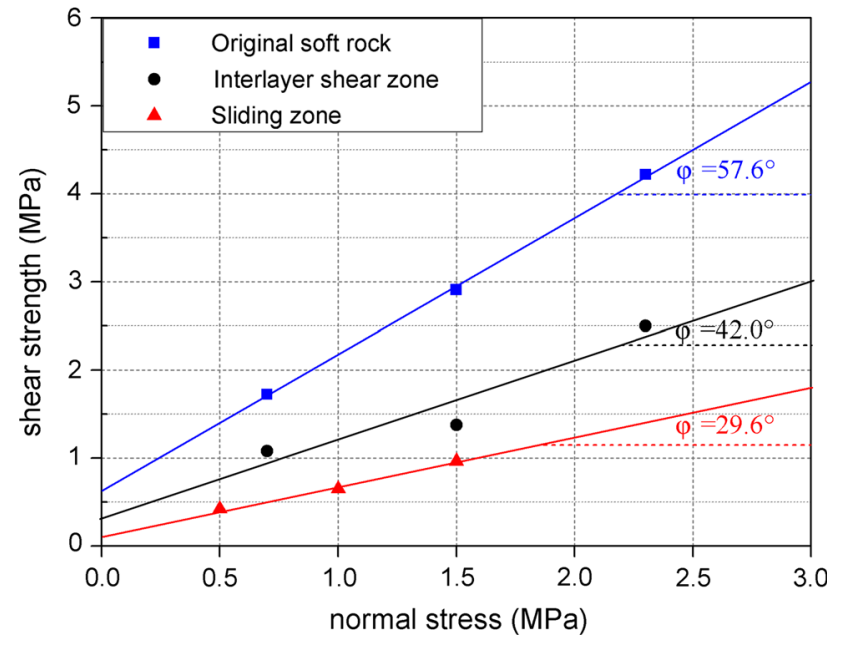

Figure 11. Curves of long-term shear strength under three stages.

identical shear stress, the creep rate of the sliding zone was greater than that of the interlayer shear zone and that of the interlayer shear zone was greater than that of the original soft rock. The shear stress and average creep rate exhibited a nonlinear relationship, which met the following functional relationship after numerical fitting:

$$
y=a+\exp \left(\frac{x-\alpha}{\beta}\right) b
$$

where $x$ is the shear stress; $y$ is the average creep rate; and $a, b, \alpha$ and $\beta$ are the material parameters of the rock as shown in table 3 .

\subsection{Shear strength analysis of long-term creep}

Through the above creep curve analysis, we plotted a long-term shear strength curve for the carbonaceous shale (figure 11). It was observed that the long-term shear strength increased with normal stress. Under identical normal stress, the long-term shear strength of the original soft rock was greater than that of the interlayer shear zone and that of the interlayer shear zone was greater than that of the sliding zone. We also calculated the longterm shear stress strength parameters (table 4).
It was observed that compared with the internal friction angle of the original soft rock, the internal friction angle of the interlayer shear zone decreased by $27.0 \%$; and the internal friction angle of the slip zone decreased by $48.5 \%$. In addition, compared with the cohesion of the original soft rock, the interlayer shear zone decreased by $45.6 \%$ and the sliding zone decreased by $83.6 \%$. Thus, it can be seen that the accumulated decrease in cohesion was greater than that of the internal friction angle. This indicates that cohesion was more sensitive to time than the internal friction angle.

\section{Creep model}

\subsection{Nonlinear damage creep model}

The displacement-time creep curve of the carbonaceous shale exhibits characteristics of initial instantaneous elastic deformation, time-dependent viscous deformation and plastic deformation at the failure stage (Shi et al. 2013). Usually, a model that combines the viscous, elastic and plastic elements can describe the initial decay creep and steadystate creep of rock specimens. However, since the basic elements comprising the model are linear, it cannot fully describe the nonlinear accelerated creep stage for the rock in the last shear stress step (Jin 1998).

According to mechanical damage theory, we introduced the damage variable $D$ and assumed that the infinitesimal strain element $D$ of the rock in the accelerated creep stage followed a Weibull distribution (Cao et al. 2004). The results are as follows:

$$
D=F(t)=1-\exp [-\varphi(t)]
$$

Since $F(t)$ should be an increasing function between 0 and 1 , we introduced $\varphi(t)$ as:

$$
\varphi(t)=\left\{\begin{array}{ll}
0, & t \leq t^{*}, \\
\left(t-t^{*}\right)^{n}, & t>t^{*},
\end{array} \quad n>0\right.
$$


Table 4. Parameters of long-term shear strength under three stages.

\begin{tabular}{lcccc}
\hline Evolutionary stages & $\sigma(\mathrm{MPa})$ & $\begin{array}{r}\text { Long-term shear } \\
\text { strength }(\mathrm{MPa})\end{array}$ & $\varphi\left(^{\circ}\right)$ & $c(\mathrm{MPa})$ \\
\hline Original soft rock & 0.7 & 1.725 & 57.6 & 0.585 \\
& 1.5 & 2.909 & & \\
Interlayer shear zone & 2.3 & 4.218 & & \\
& 0.7 & 1.080 & 42.0 & 0.318 \\
Sliding zone & 1.5 & 1.375 & & \\
& 2.3 & 2.500 & & \multirow{2}{*}{0.096} \\
& 0.5 & 0.423 & 29.6 & \\
\hline
\end{tabular}

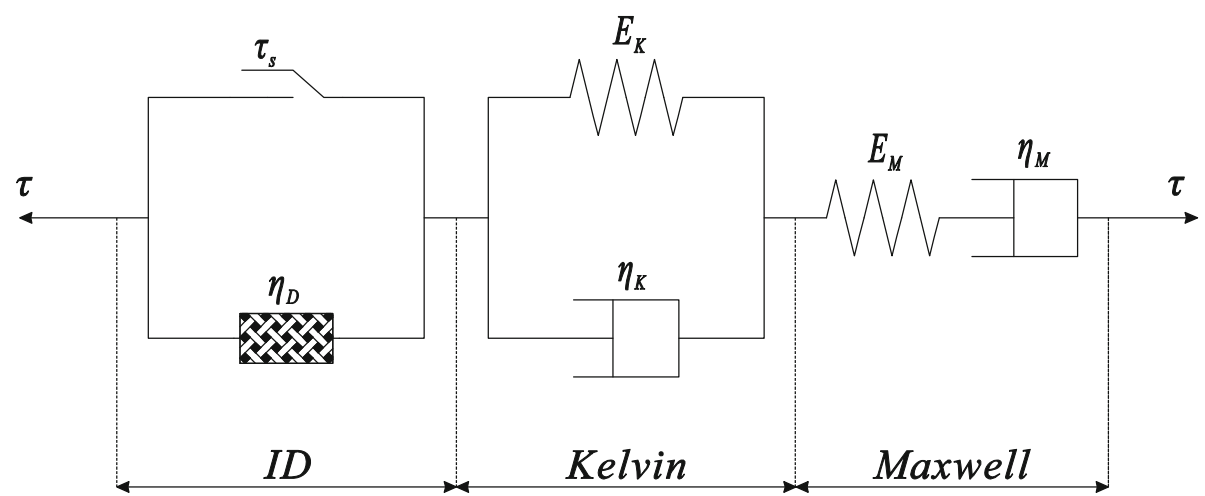

Figure 12. Nonlinear damage creep model.

After obtaining the accelerated creep of the rock at time $t$, the internal damage variable is

$$
\begin{aligned}
D & =F(t) \\
& =\left\{\begin{array}{ll}
0, & t \leq t^{*}, \\
1-\exp \left[-\left(t-t^{*}\right)^{n}\right], & t>t^{*},
\end{array} \quad n>0,\right.
\end{aligned}
$$

where $D$ is the damage variable, $t$ is the creep time, $n$ is a constant and $t^{*}$ is the start time of the nonlinear creep of the rock. When $t \leq t^{*}$, the rock samples are in the steady-state creep stage, and the corresponding damage variable $D$ goes to zero. When $t>t^{*}$, the rock sample enters the nonlinear accelerated creep stage from the steady-state creep stage, and the damage variable $D$ eventually approaches 1 over time.

The damage variable $D$ is connected in parallel with a plastic element to comprise a nonlinear damage visco-plastic model $I D$, which is used to describe the accelerated creep stage of the carbonaceous shale. Based on the Burgers creep model (Burgers creep model consists of a Kelvin model and a Maxwell model), the nonlinear damage viscoplastic model $I D$ is connected in parallel with the Burgers model to establish an improved Burgers nonlinear visco-elastic-plastic creep model, which can represent the initial creep stage, steady-state creep stage and accelerated creep stage of the carbonaceous shale (Wang et al. 2012), as shown in figure 12.

In the model, $\tau$ is the shear stress, $E_{\mathrm{M}}$ is the instantaneous elastic modulus in the initial creep stage, $E_{\mathrm{K}}$ is the elastic modulus of the steady-state creep stage, $\eta_{\mathrm{K}}$ is the viscosity coefficient, i.e., the speed rate of creep deformation tending to steady state, $\eta_{\mathrm{M}}$ is the creep rate in the steady-state creep stage, $\eta_{\mathrm{D}}$ is the viscosity coefficient of the accelerated creep stage and $\tau_{\mathrm{s}}$ is the long-term shear strength of the rock.

The total creep deformation could be represented as:

$$
u=u_{\mathrm{M}}+u_{\mathrm{K}}+u_{\mathrm{a}},
$$

where $u_{\mathrm{M}}$ is the creep deformation in the Maxwell model, $u_{\mathrm{K}}$ is the creep deformation in the Kelvin model, $u_{\mathrm{a}}$ is the accelerated creep deformation due to damage; hereinafter the impact of the initial creep stage and the steady-state creep stage on the damage is not considered.

The creep equation of the Maxwell model is

$$
u_{\mathrm{M}}=\frac{\tau}{E_{\mathrm{M}}}+\frac{\tau}{\eta_{\mathrm{M}}} t
$$


and the creep equation of the Kelvin model is

$$
u_{\mathrm{K}}=\frac{\tau}{E_{\mathrm{K}}}\left[1-\exp \left(-\frac{E_{\mathrm{K}}}{\eta_{\mathrm{K}}} t\right)\right] .
$$

The ID creep equation of the visco-plastic nonlinear damage model is

$$
u_{\mathrm{a}}=\frac{\tau-\tau_{\mathrm{s}}}{\eta_{\mathrm{D}}} \exp \left[\left(t-t^{*}\right)^{n}\right] t .
$$

When $0<\tau<\tau_{\mathrm{s}}$, only the Maxwell model and the Kelvin model work, and the nonlinear damage model $I D$ does not work. The model degrades into the Burgers model, and the corresponding creep equation is

$$
u=\frac{\tau}{E_{\mathrm{M}}}+\frac{\tau}{\eta_{\mathrm{M}}} t+\frac{\tau}{E_{\mathrm{K}}}\left[1-\exp \left(-\frac{E_{\mathrm{K}}}{\eta_{\mathrm{K}}} t\right)\right] .
$$

When $0<\tau_{\mathrm{s}}<\tau$ and $t<t^{*}$, the damage variable $D$ the in the model does not work, and the corresponding creep equation is

$$
\begin{aligned}
u= & \frac{\tau}{E_{\mathrm{M}}}+\frac{\tau}{\eta_{\mathrm{M}}} t+\frac{\tau}{E_{\mathrm{K}}}\left[1-\exp \left(-\frac{E_{\mathrm{K}}}{\eta_{\mathrm{K}}} t\right)\right] \\
& +\frac{\tau-\tau_{\mathrm{s}}}{\eta_{\mathrm{D}}} t .
\end{aligned}
$$

When the shear stress obeys $0<\tau_{\mathrm{s}}<\tau$, and $t>$ $t^{*}$, the various elements and the damage variable $D$ in the model work, and the corresponding creep equation is

$$
\begin{aligned}
u= & \frac{\tau}{E_{\mathrm{M}}}+\frac{\tau}{\eta_{\mathrm{M}}} t+\frac{\tau}{E_{\mathrm{K}}}\left[1-\exp \left(-\frac{E_{\mathrm{K}}}{\eta_{\mathrm{K}}} t\right)\right] \\
& +\frac{\tau-\tau_{\mathrm{s}}}{\eta_{\mathrm{D}}} \exp \left[\left(t-t^{*}\right)^{n}\right] t
\end{aligned}
$$

where $n$ represents the magnitude of the creep rate in the nonlinear accelerated stage of the rock. Equation (11) is the improved Burgers nonlinear damage creep model.

\subsection{Model validation}

Based on the experimental data for the full creep shear process of the samples are used to verify the improved Burgers nonlinear creep damage model by using the Levenberg-Marquardt nonlinear optimisation least-squares method, and obtain the corresponding creep model parameters (Liu and Sun 1998). The mechanical creep parameters when the normal stress is $1.5 \mathrm{MPa}$ are shown in table 5 .

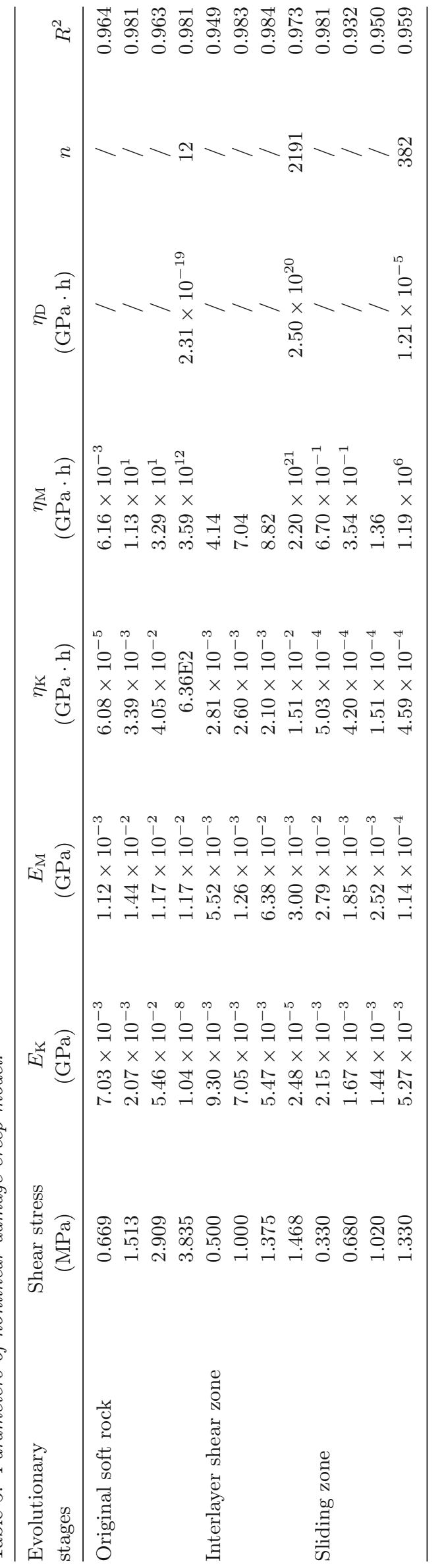



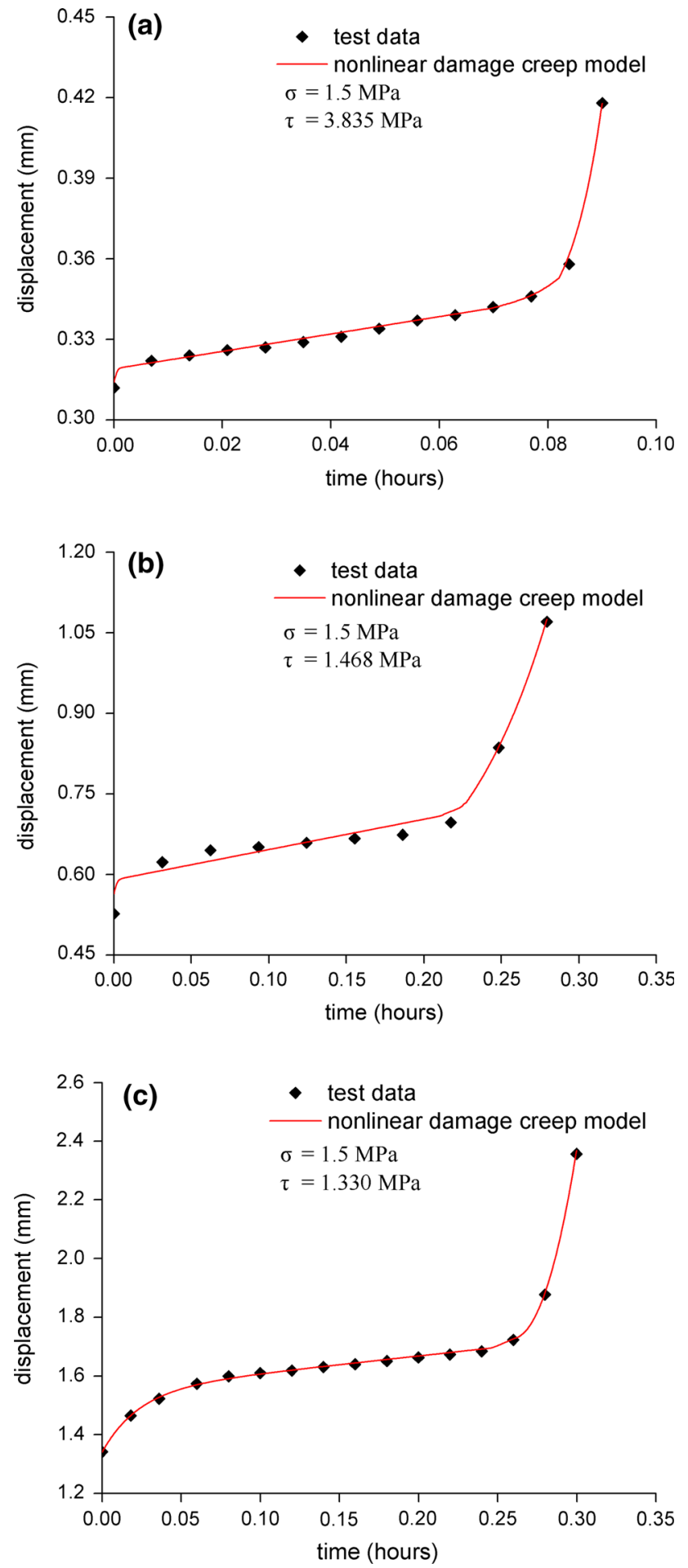

Figure 13. Comparison between nonlinear damage creep model and test results: (a) shows the curve of original soft rock; (b) shows the curve of the interlayer shear zone; and (c) shows the curve of the sliding zone.

Through the analysis of the data in table 5 , it was concluded that the original soft rock, the interlayer shear zone and the sliding zone had different microstructures and uneven joint fissures, therefore, under identical normal stress, the creep parameters of the three stages exhibited a certain amount of discrepancy, and their magnitudes were not identical. However, for a single sample, the creep parameters exhibited a certain regularity with increasing shear stress. For example, when the shear stress was loaded from the first level to the third level, the increase or decrease of parameter $E_{\mathrm{M}}$ varied with increasing shear stress. This variation was due to differences in the development of microcracks and other defects inside rock samples. $E_{\mathrm{K}}$ gradually increased with increasing shear stress. This indicates that creep hardening occurred in the rock samples and that the sample's resistance to deformation gradually increased. $\eta_{\mathrm{M}}$ gradually increased with increasing shear stress. This also validated the causes of variation in the shear creep rate. $\eta_{\mathrm{K}}$ represents the speed rate when the deformation tended to be in steady state during the creep stage. A larger value of $\eta_{\mathrm{K}}$ indicated that the rock would take longer to reach the steady state.

Figure 13 shows a comparison between the fitting curve and the experimental data when $\sigma=$ 1.5 $\mathrm{MPa}$ during the last shear stress step. It was observed that the model can fully represent the full creep process of the carbonaceous shale, and it can describe the nonlinear characteristics of the accelerated creep stage better. The model fitting curve matched the experimental data well, and the goodness-of-fit was $0.932-0.984$.

\section{Discussion}

The change of clay mineral content in carbonaceous shale is due to the change of minerals under certain conditions, and it is also related to the content of parent rock samples. In the shear plane, there is a directional striation, which represents the creep direction of a certain period of the rock formation. The shear creep test results show that the creep shear displacement, rate and long-term shear strength of carbonaceous shale have certain regularity. This may be due to differences in mineral composition and microstructure in the samples. Through the analysis presented in this paper, the evolutionary characteristics of the carbonaceous shale are concluded to be as follows (figure 14):

(1) Original soft rock ( $\mathrm{Li}$ et al. 2004): The original soft rock is a carbonaceous shale, it has a layered structure, imperfect development and locally clamped with limestone lens. Due to 


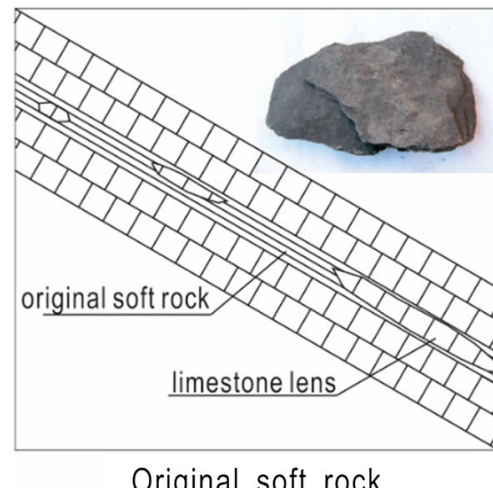

Original soft rock

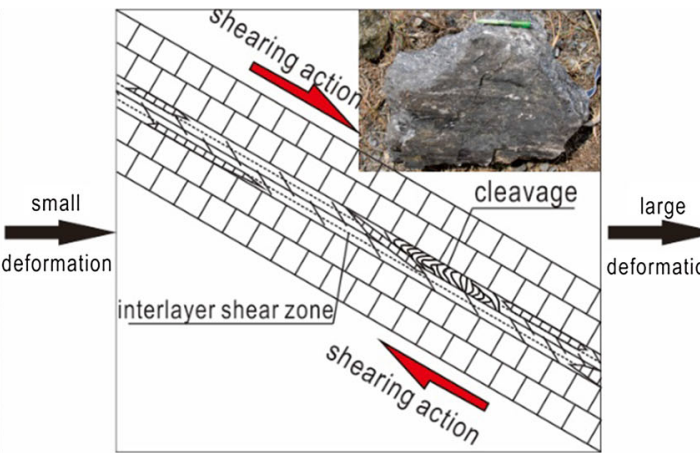

Interlayer shear zone

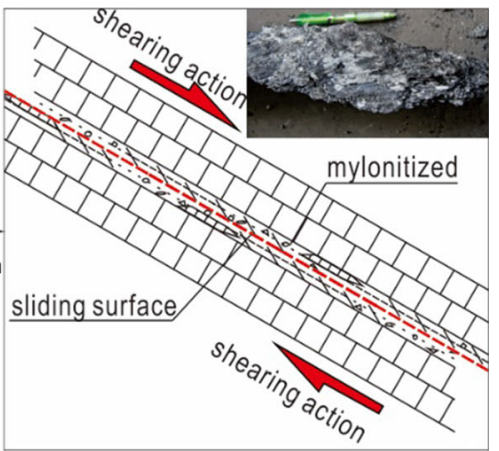

Sliding zone

Figure 14. Sketch of evolutionary stages of the Permian carbonaceous shale.

the slight impact of the tectonic movement, the cementation of the original soft rock is better, but it has a small amount of low-angle fractures. In addition, it has a higher long-term shear strength: the internal friction angle is $57.6^{\circ}$ and the cohesion is $0.585 \mathrm{MPa}$.

(2) Interlayer shear zone (Xu and Han 1993): The interlayer shear zone is carbonaceous shale with calcite veins. It is mainly affected by internal dynamic geological processes such as tectonic movement. Stress is concentrated at the interface between the hard rock and soft rock or inside the soft rock, and leads to a small shear deformation. In addition, the long-term shear strength decreases: the internal friction angle is $42.0^{\circ}$ and the cohesion is $0.318 \mathrm{MPa}$.

(3) Sliding zone (Wang et al. 2004): The sliding zone is carbonaceous shale with the local siltized phenomenon. It is mainly affected by gravity, groundwater and other external dynamic geological effects. Besides, a large shear deformation occurs. The friction mirror can be seen at the surface of the rock. In addition, the long-term shear strength further decreases: the internal friction angle is $29.6^{\circ}$ and the cohesion is $0.096 \mathrm{MPa}$.

\section{Conclusions}

Through studying the mineral compositions, microstructures and shear creep mechanical characteristics of the carbonaceous shale, we draw the following conclusions:

(1) During the evolution of the carbonaceous shale, the clay mineral content gradually increased, from less than $5 \%$ in the original soft rock to between $5 \%$ and $10 \%$ in the interlayer shear zone to greater than $10 \%$ in the sliding zone.
The microstructure became loose from being compacted, and the bonding force between the particles decreased, and the number of pores and joint fissures increased.

(2) Under identical normal stress, the creep displacement and rate of the carbonaceous shale increased with increasing shear stress and exhibited a nonlinear relationship. When the shear stress was a constant value, the creep displacement and rate of the sliding zone were greater than those of the interlayer shear zone and those of the interlayer shear zone was greater than those of the original soft rock. During the evolution of the carbonaceous shale, the long-term shear strength gradually decreased, and the decline in the magnitude of cohesion was greater than that of the internal friction angle. This indicates that the cohesion was more sensitive to time than internal friction angle.

(3) We introduced a damage variable and established an improved Burgers nonlinear damage creep model. Our model can successfully represent the full creep deformation process of the original soft rock, the interlayer shear zone and the sliding zone. The model fitting curve matched the experimental results well, and identified and obtained the model creep parameters. This model can provide information for the analysis of the mechanical creep characteristics of other types of the carbonaceous shale.

\section{Acknowledgements}

This research was supported by the National Natural Science Foundation of China (No. 41472295) and the National Land Resources Survey of China (Nos. 12120114079101, DD20179609). 
The authors express their gratitude to the Associate Editor Saibal Gupta and the anonymous reviewers for their valuable suggestions to improve the paper.

\section{References}

Cao W G, Zhao M H and Liu C X 2004 Study on the model and its modifying method for rock softening and damage based on Weibull random distribution; Chin. J. Rock Mech. Eng. 23(19) 3226-3231.

Chen F X and Xiao J Q 1955 Summary report of surface geological works in Tiejianggou mining area of Wulong on 1954; No. 721 team of Southwest Steel Co. Ltd.

Desai C S and Zhang D 1987 Viscoplastic model for geologic materials with generalized flow rule; Int. J. Numer. Anal. Met. 11(6) 603-620.

Feng Z, Yin Y P, Li B and Zhang M 2012 Mechanism analysis of apparent dip landslide of Jiweishan in Wulong, Chongqing; Rock Soil Mech. 33(9) 2704-2712.

Griggs D T 1939 Creep of rock; J. Geol. 47 225-251.

Gu D Z 1983 Foundations of engineering geomechanics of rock mass; Science Press, Beijing, pp. 200-214.

Jin F N 1998 Rock nonlinear rheology; Hohai University Press, Nanjing.

L'Heureux J S, Longva O, Steiner A, Hansen L, Vardy M E, Vanneste M, Haflidason H, Brendryen J, Kvalstad T J, Forsberg C F, Chand S and Kopf A 2012 Identification of weak layers and their role for the stability of slopes at Finneidfjord, Northern Norway; In: Advances in Natural and Technological Hazards Research (eds) Yamada Y, Kawamura K and Ikehara K et al., Springer, The Netherlands, vol. 31, pp. 321-330.

Li K R and Kang W F 1983 Creep testing of thin interbedded clayey seams in rock and determination of their long-term strength; Rock Soil Mech. 4(1) 39-46.

Li H S, Wang X K and Li L 2002 Specification of geological map in Chongqing; Chongqing Geological and Mineral Exploration and Development Co. Ltd., Chongqing.

Li S D, Li X, Zhang N X and Liao Q L 2004 Sedimentation characteristics of the Jurassic sliding-prone stratum in the Gorges Reservoir area and their influence on physical and mechanical properties of rock; J. Eng. Geol. 12(4) 385389.

Li X, Li S D, Chen J and Liao Q L 2008 Coupling effect mechanism of endogenic and exogenic geological processes of geological hazards evolution; Chin. J. Rock Mech. Eng. 27(9) 1792-1806.

Li B, Wang G Z, Feng Z and Wang W P 2015 Failure mechanism of steeply inclined rock slopes induced by underground mining; Chin. J. Rock Mech. Eng. 34(6) 1148-1161.
Liu B G and Sun J 1998 Identification of rheological constitutive model of rock mass and its application; $J$. Beijing Jiaotong Univ. 22(4) 10-14.

Maranini E and Brignoli M 1999 Creep behavior of a weak rock: Experimental characterization; Int. J. Rock Mech. Min. 36(1) 127-138.

Paul F and Christian C 1996 Improvements by measuring shear strength of weak layers; Instrum. Meth. 158-162.

Perzyna P 1966 Fundamental problems in visco-plasticity; Adv. Appl. Mech. 9(2) 244-368.

Qu Y X and Xu R C 1983 Study of interbedding shear zone at Gezhouba project on the Yangtze River; Science Press, Beijing, pp. 161-168.

Savage W Z and Varnes D J 1987 Mechanics of gravitation a spreading of steep-sided ridges; Eng. Geol. 35 31-36.

Shi C P, Feng X T, Jiang Q and Xu D P 2013 Preliminary study of microstructural properties and chemical modifications of interlayer shear weakness zone in Baihetan; Rock Soil Mech. 34(5) 1287-1292.

Sun J 2007 Rock rheological mechanics and its advance in engineering applications; Chin. J. Rock Mech. Eng. 26(6) 1081-1106.

Tan T K and Li K R 1994 Relaxation and creep properties of thin interbedded clayey seams and their fundamental role in the stability of dams; Fujian Science Press, Fujian, pp. 369-374.

Wang H X, Tang H M and Yan T Z 2004 Study on X-ray diffraction for the orientability of clay minerals in slidingsoil in the Miaoshangbei landslide, Xiaolangdi reservoir area; J. Miner. Petrol. 24(2) 26-29.

Wang Y, Li J L, Deng H F and Wang R H 2012 Investigation on unloading triaxial rheological mechanical properties of soft rock and its constitutive model; Rock Soil Mech. 33(11) 3338-3344.

Xiao S F, Wang X F, Cheng Z F and Nie L 1987 The creep model of the intercalated clay layers and the change of their microstructure during creep; Chin. J. Rock Mech. Eng. 2 471-478.

Xu W Y and Han G Q 1993 Study on the weakenly shearing interlaying zone in Gaobazhou damsite; J. Chin. Three Gorges Univ. 15(2) 3-15.

Xu D P, Feng X T, Cui Y J, Jiang Q and Zhou H 2012 On failure mode and shear behavior of rock mass with interlayer staggered zone; Rock Soil Mech. 33(1) 129-136.

Yin Y P, Kang H D and Zhang Y 2000 Stability analysis and optimal anchoring design on Lianziya dangerous rockmass; Chin. J. Geotech. Eng. 22(5) 599-603.

Yin Y P, Sun P, Zhang M and Li B 2011 Mechanism on apparent dip sliding of oblique inclined bedding rockslide at Jiweishan, Chongqing, China; Landslides 8(1) 49-95.

Zhu Y B and Yu H M 2014 An improved Mesri creep model for unsaturated weak intercalated soils; J. Cent. South Univ. 21 4677-4681.

Zienkiewicz O C and Cormeau I C 1974 Visco-plasticity and creep in elastic solids - A unified numerical solution approach; Int. J. Numer. Meth. Eng. 8(4) 821-845. 